Moustafa A. Mekawy

\title{
A Constructivist Grounded Theory Investigation of Businesses' Concerns About Public-Private Partnership Responses Toward COVID-19
}

\section{Abstract}

Peripheral destinations in Egypt face public-private partnership (P3) response challenges during COVID-19. The proposed partnership policies and solutions of governments seem inadequate and reflect a lack of agility. This constructivist grounded theory (GT) study aims to investigate businesses' perceptions and concerns that may affect reshaping the P3 strategies of Egypt's tourism-related government departments at Marsa Alam, Egypt. The period under investigation is May 2020 to July 2020, when COVID-19 was causing a fundamental change in Egypt's tourism industry. The findings show that employees' rights, businesses' priorities, destinations' recovery challenges, and making P3 more joined-up are significant concerns in the recovery, restart, and agile $\mathrm{P} 3$ responses of peripheral destinations. This study investigates $\mathrm{P} 3$ management and considers its application in the wake of global health crises, where agile P3 practices are lacking.

Keywords: public-private partnership, tourism industry, vulnerable businesses, peripheral destination, COVID-19, Egypt

\section{Introduction}

Partnership is defined as an agreement where two or more partners (from the private, public, and/or mixed sectors) agree to collaborate to achieve their mutual interests (Chaperon, 2017). In the tourism field, publicprivate partnerships ( $\mathrm{P} 3 \mathrm{~s}$ ) have often been recognized as a means of cooperation (Organisation for Economic Co-operation and Development [OECD], 2020) that seeks to foster tourism development (Chaperon, 2017) by drawing on the success achieved by partners to help deliver sustained growth for tourism-connected enterprises on a national level, while ensuring that government agencies address the critical needs of the national private sector (Wondirad et al., 2020). In reality, however, it is common to detect a distinction-between business and government people-in interpreting this understanding, mainly due to differences in individuals' perceptions toward P3s' priorities (Dewulf \& Garvin, 2019).

Practically, this difference will be exacerbated when identifying and interpreting businesses' concerns while neglecting the key variations between destinations' contexts and businesses' priorities in terms of traced P3 outcomes (Wondirad et al., 2020) during pandemics (United Nations World Tourism Organization [UNWTO], 2020). Pandemics, such as COVID-19, create rare global tourism system challenges that essentially encourage provisional and durable $\mathrm{P} 3 \mathrm{~s}$ to fix problems in the tourism business environment, tourism employment security, and destination durability (Ivanov et al., 2020; Zenker \& Kock, 2020). The tourism challenges presented by pandemics may be universal (e.g., in terms of cancellation of travel and declining tourism revenues), but also context-sensitive, as different destinations (i.e., core and peripheral) have different capabilities to handle these challenges, along with many priorities (Zenker \& Kock, 2020). Hence, the key question that will be investigated is: What are peripheral destinations' businesses' biggest concerns about P3s in the context of the COVID-19 crisis?

Moustafa A. Mekawy, PhD, Corresponding author, Tourism Studies Department, University of Sadat City, El Sadat City, Egypt; ORCID ID: https://orcid.org/0000-0001-6999-7871; e-mail: mustafa.mekkawy@fth.usc.edu.eg

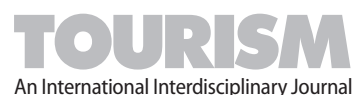


Agile P3s are frequently acknowledged as a policy priority for destination development programs (Williams et al., 2020). However, how agile P3 can be used as a useful approach to ease entrepreneurs' concerns in a fast-changing world - a world in which these entrepreneurs are eagerly awaiting a return to the 'new normal' (Carr, 2020)—is still being explored by governments, private businesses, and international tourism organizations. This challenge entails a critical gap in the research brought about by the agility matters and concerns of $\mathrm{P} 3$ s in the context of those peripheral destinations that combat pandemics (Williams et al., 2020). Hence, the main purpose of this study is to identify those business concerns that may affect reshaping P3s at peripheral destinations, in an agile way, during COVID-19.

This study represents a significant contribution to promoting P3s' real-time information exchange to combat COVID-19, as well as reporting on the best methods for future pandemics in peripheral destinations. Furthermore, this study will use a constructivist GT approach to guide how to categorize businesses' concerns about $\mathrm{P} 3$ in the context of a particular peripheral destination. Businesses' insights regarding P3 issues, destination exposure, the business vulnerability in times of crisis, and other relevant features — along with cutting-edge P3 approaches in the tourism literature and the valuable approach of conducting P3s - are first reviewed to help produce an outline of the principal topics from the perspective of the affected businesses. The methodology is then itemized, and conclusions are presented using the proposed sub-topics. Finally, the study's implications have been noted for further examination.

\section{Literature review}

Using relevant literature, this chapter will discuss the ideas of business concerns, P3 responses, destination exposure, and business vulnerability, as well as the Joined-Up approach.

\subsection{Businesses' concerns about P3's real-time responses}

Despite the business-evident advantages and stimulus to P3 strategies, notable concerns also endure among tourism entrepreneurs. Chaperon (2017) identified businesses' more frequent concerns about P3 strategies as a lack of consideration as to how to meet employees' rights at the lowest possible losses and the absence of estimating businesses' perceptions toward required levels of public-private cooperation. It is contended that while these concerns exist, the strategy that they are recognized and approached nationally has been confined by the absence of consultation of Egyptian tourism entrepreneurs and employees.

Prevailing national perceptions do not mirror the increasing worldwide trends of $\mathrm{P} 3 \mathrm{~s}$ in peripheral destinations. Rather, many scientists have shown that most of today's global threats drive people to escape congestion (Zenker \& Kock, 2020). This tendency could induce a change in tourists' mindsets regarding travel behavior, leading to a strategic shift from congested popular destinations to more peripheral and underpopulated destinations (Zenker \& Kock, 2020). This implies that peripheral destination businesses have a 'moral responsibility' for their employees; businesses must do everything possible to maintain their employees' health, security, and wellbeing amid the pandemic (OECD, 2020). However, this moral responsibility is costly; health care costs might become detrimental to employees' workplace rights, and they will be exposed to layoffs, which is considered an unpremeditated first measure to lessen expenses in times of global crisis (UNWTO, 2020). Therefore, before announcing new P3 strategies, governments should reflect on these measures early to align employees' rights and business concerns successfully.

Due to its effectiveness in promoting cooperation between public and private interests and resources, the theory of P3 has received a lot of attention in the tourism governance literature (Dewulf \& Garvin, 2019). P3 is not, however, a panacea for all businesses' goals and recovery challenges; it is only one of many governance approaches. In this vein, Hall (2011) stated that there are two distinct approaches to governance. First, governance is a term that describes how a modern state adapts to its economic and political environment in




terms of how it operates. Second, it refers to a conceptual and theoretical representation of the state's position in coordinating socio-economic structures. Consequently, the argument here is that recognizing governance theory is significant because it provides a political economy framework in which emerging governing mechanisms can be understood, and it is critical to the creation of a deep understanding of public-private tourism partnership concerns (Hall, 2011).

Further, many studies suggest that not all businesses' concerns relate only to meeting employees' rights and leveraging levels of public-private cooperation; other concerns, like the renewed role of government, publicprivate trust, thinking geographically, funding, and business vulnerability to unexpected crises must also be recognized (Chaperon, 2017; UNWTO, 2020).

\subsection{Peripheral destinations' exposure and businesses' vulnerability}

The notion of 'core-periphery construct' is a classic knowledge paradigm for detailing and interpreting different types of diversity through place, time, community, etc. (Prideaux, 2002). Unlike "core destination", which considers retaining the power to manage tourist flows, tourism investments, tourism development, transport planning, employee mobility, and the position of public utilities (Schmallegger et al., 2010), 'peripheral destination' has been defined as a non-urban tourist spot, or one which is located geographically far from main residential areas, which is fit for providing products or big tourism-generating markets (Pociūtė-Sereikiené, 2019; Prideaux, 2002). To successfully formulate P3s that aim to handle tourism crises and pandemic ramifications, governments and tourism businesses must have gained an adequate knowledge-base about destination traits that are rooted in relevant definitions, notions, experiences, and pertinent exposure characteristics.

This study contemplates presenting that knowledge and assessment by further analyzing the traits-based causes of the threat, as presented below. However, this contribution does not investigate peripheral tourism destinations per se. Rather, it is built on the premise that global crises, which are intrinsically unstable on several time-frames, may dramatically change in coming years and that such occurrences have implications for the tourism industry's businesses and employees in peripheral destination contexts (Mekawy, 2019; OECD, 2020).

In their attempts to validate the role of peripheral destinations' geographical remoteness and economic fragility in intensifying tourism vulnerability to global crises, earlier investigations have verified a distinct connection between the capacities of inflexible P3s, overlooking dimensions of exposure and vulnerability, and misreading and misjudging the evolving pattern of destinations' exposure and businesses' vulnerability (Carr, 2020). However, while these traits envisage the extent to which these types of tourism exposure aid vulnerability (Lai $\& \mathrm{Li}, 2012$ ), they do not particularize the procedures delineating the ability of an individual or business to contemplate, handle, combat, and mend the influence of a crisis peril.

Arguably, the 'tourism vulnerability' concept has appeared as a means of attempting to explain hazards faced by the tourism industry and its businesses, people, and destinations, despite numerous variables that can determine vulnerability and its spatio-temporal extent. Vulnerability and resilience have also been related in the literature, though the existence of the connection has been disputed (Carr, 2020). In the tourism context, vulnerability is about the inclination of imperiled elements of the industry-such as employees, their livelihoods, and businesses - to bear the harmful consequences of perilous situations (OECD, 2020). The term "vulnerable system" can be used to describe a system that has lost its resilience (Carr, 2020). As a result, strengthening destination resilience by agile P3 solutions to cope with and handle pandemic threats has been highlighted as critical to recognizing and reducing vulnerability.

For decades, the term "resilience" has been intensely discussed across disciplines (Martin et al., 2016). Given the paper's focus on vulnerable businesses fighting pandemics in peripheral destinations, the paper places a strong emphasis on understanding resilience from a spatial/regional socio-economic perspective at the destination/systems level. In this vein, Martin et al. (2016) asserted that regional resilience refers to a region's 
(destination's) capacity to absorb instability and disruptions from both the inner and outer. Uncertainty occurs in local populations and economies due to constant exposure to shocks, threats, and tension, such as the threat of a global pandemic (Prideaux, 2002). For that reason, new P3 strategies should focus on stopping tourism industry elements (i.e., peripheral destinations' businesses and employees) from becoming vulnerable or suffering exposure.

\subsection{Upgrading tourism P3s with a joined-up approach}

In the context of $\mathrm{P} 3 \mathrm{~s}$ and pandemic crises, many peripheral destination communities, mostly in developing countries, find strategic cooperation with government agencies annoying, disconnected, and not combined (OECD, 2020; Schmallegger et al., 2010), rendering these peripheral destinations less attractive for enterprises to invest in the tourism industry, particularly in times of uncertainty (Prideaux, 2002). Thus, one might wonder what approach government agencies should take to mitigate the COVID-19 crisis's impact on peripheral destinations' tourism businesses and individuals.

Notably, there is no one-size-fits-all solution to the COVID-19 crisis, but instead a range of solutions that, if applied in relevant time and sequence, might produce a collaborative and practical P3 response, as well as agile mitigation and resilience strategies (OECD, 2020). To achieve this, a joined-up approach (Huxham \& Vangen, 2000) to aid development in priority vulnerable industry elements, like business recovery (Čorak et al., 2020) and resilience or employee retention, would help protect and strengthen them in this main industry (OECD, 2020). A joined-up approach means creating a holistic framework for leading government-wide engagement with exposed industry elements in vulnerable areas, like peripheral destinations (Huxham \& Vangen, 2000). By and large, this approach implies including individuals who live and work in a peripheral destination and constituencies connected to P3's ambitions (see Huxham \& Vangen, 2000).

In this approach, tourism P3s' actors develop a group of common principles for better engagement in peripheral destinations to promote combined improvement across the protection, stimulus, recovery, marketing, logistic, and executive domains (Wondirad et al., 2020). By augmenting their socio-economic protection and offering extended peripheral businesses and employees relief from tourism P3s' gains, this approach helps to prevent vulnerable businesses and employees from being overwhelmed. Therefore, tourism-relevant government agencies should reconsider the joined-up approach as an avenue for ameliorating tourism P3s' development in peripheral destinations in chaotic times (Huxham \& Vangen, 2000).

\section{Method}

\subsection{Research design}

This study adopts a constructivist GT approach as proposed by Charmaz (2014) to assess how P3s are being pursued in the resort of Marsa Alam, Egypt, a peripheral destination susceptible to tourism growth during past years owing to its sunny beach holidays. Peripheral destinations' businesses' perceptions toward the rethinking of $\mathrm{P} 3 \mathrm{~s}$ are hardly ever placed in a valid theoretical context in the wake of pandemics (Chaperon, 2017). GT methodology is considered a suitable tool for better understanding a structured rapport between social stakeholders and how the rapport and collaborations vigorously create actuality (Wondirad et al., 2020).

GT is increasingly being used to reveal informants' true contexts and emotional interests (Creswell, 2014). It allows tourism development and planning scholarships to recognize the interpretation of the phenomena under research to co-create realities using methodologically collected and analyzed data. People's concerns and experiences may eventually be revealed due to using GT (Charmaz, 2014).

According to Charmaz (2015), GT is a set of systematic inductive procedures for performing qualitative research to develop theories. Accordingly, the study explored the perceptions of tourism businesses in peripheral 
destinations toward P3s better to understand COVID-19's impact on the future of P3s and to help generate new notions about this phenomenon. This mission entails adopting a qualitative interviewing approach, encouraging participants to provide important details about the phenomena under examination while leaving elucidation and investigation to the investigators (Creswell, 2014). In this context, the semi-structured Skype interview technique was utilized as a tool for collecting data. This method was intended to establish a better understanding of peripheral destination businesses' perceptions about increased concerns during the coronavirus outbreak-especially those concerns regarding the operationalization of P3s and how they see the impact that such concerns and/or their solutions have on the future of the P 3 s and future pandemic crises (Hanna, 2012).

Furthermore, the five basic tenets of GT that could be used as a tool for theory building were adopted in this study based on Gibson and Hartman's (2014) work. The openness of GT is the first precept, which can be confirmed by looking at the investigators' avoidance of preconceptions. This principle implies that a specific theoretical agenda should not drive investigation and that research questions should be open during the investigation. Explanatory power is the second precept of the GT method. This principle implies that research must be trustworthy and relevant to society and that GT must be formed by local concerns. The balance between the generation and justification of GT is the subject of the third tenet. As a result, this research concentrated on generating insights into the phenomenon at hand rather than justifying predetermined notions. The fourth principle is theory structure, which relates to a collection of empirical evidence linked to core categories, where categories are identified and compared to one another. The repetition of the research process, in which data collection and interpretation are integrated adaptively, is the fifth principle of GT (Matteucci \& Gnoth, 2017).

The sudden appearance and impact of the COVID-19 crisis on the tourism industry require scholars, businesses, and government officials to identify logical explications for emergent problematic issues in implementing P3s' priorities and relevant policy-making issues. Consequently, the constructivist position (Pernecky \& Jamal, 2010) is used to grasp the reality of emerging P3 concerns post-COVID-19 from the viewpoint of peripheral destinations' businesses. Various schools of thought about the use of GT have been identified in previous studies. However, all GT approaches, whether objectivist, post-positivist, or constructivist, take a realist ontological standpoint, making the argument that reality occurs separately of the participant (Matteucci \& Gnoth, 2017). According to Matteucci and Gnoth (2017), the constructivist GT approach is viewed as a vessel with the specific ability to produce useful insights from a variety of sources and facts, such as records, audio-visual images, narrative, interviews, and so on, allowing the researcher to organize the comprehensive and substantive features of reality and thus understand complex social phenomena.

As a result, the constructivist version of GT is seen useful in allowing emergent ideas to be confirmed within the sense of a substantive theory, which is characterized as an empirical field of sociological inquiry that is specific to individuals and communities (Matteucci \& Gnoth, 2017). Through understanding and integrating the categories, the substantive theory allows for a holistic view of the phenomenon (Charmaz, 2014). Thus, It is possible to find out the various linkages between theoretical categories from this perspective, as shown in Table 1.

\subsection{Population and sampling}

The population comprised all tourism business entrepreneurs and executives of Marsa Alam, Egypt, which amounted to 145 people at the beginning of this study (March 2020). This population, which has been working at the Marsa Alam destination for more than one year prior to the COVID-19 outbreak, and explicitly or implicitly availed themselves of the $\mathrm{P} 3$ s considered eligible due to their practical experience in the handling of partnership issues, were thus prepared to engage in the interview. Marsa Alam's tourism businesses, other than travel agencies (grade A), 4- and 5-star hotels, and resorts such as dive centers, safaris, excursion companies, tourist restaurants, and cafes, were precluded from the study. The target population included all experienced 
P3 entrepreneurs and executives who are registered in the Egyptian Tourism Federation database and are still working at the Marsa Alam destination.

Altogether, 62 tourism entrepreneurs and executives were contacted by email to request participation in a 30-minute Skype interview to examine their thoughts, perceptions, and attitudes toward the challenges that have shaken P3s after COVID-19. Only 43 responded, with 26 participating in the interviews, for a response rate of $41.9 \%$. According to Creswell (2014), a 40\% or higher response rate is considered healthy for online interviews. The study applied a convenience sample, in which participants were determined as regards their suitability and availability (Etikan et al., 2016), which was considered relevant due to the need to recruit participants between May 2020 and July 2020. This period witnessed imposed government measures to stop COVID-19 from spreading, including the suspension of international air traffic in Egypt's airports and a partial curfew (UNWTO, 2020).

\subsection{Data collection instruments and techniques}

Normally, GT research employs face-to-face interviews to gather primary information concerning the viewpoints and approaches of participants (Charmaz, 2014). However, due to COVID-19 social distancing restrictions, this study utilized the Microsoft Skype video-calling technique to reproduce the direct interviews (Hanna, 2012) practically. Hanna (2012) asserted that regardless of virtual interviewing challenges (e.g. inadequate internet links and interviewees' inability to use Skype technology); the Skype-to-Skype call is interchangeable with face-to-face interviewing and can consider data to be gathered over remote geographical regions.

The semi-structured Skype interview technique (Hanna, 2012) embraces Skype-to-Skype semi-structured interviews while acknowledging audio-visual notes, e-copies of business releases, pamphlets, and related reports (Sweidan, 2015). Additionally, the Skype-to-Skype semi-structured interviews helped record and understand the participants' non-verbal interactions (Hanna, 2012). The audio-visual recordings were then transcribed into a textual form so that they could be carefully explored, accompanied by explanatory comments, and/or coded. This method allowed the researcher to elaborate more on the participants' rejoinders. However, the central argument here is that transcribing is an interpretation activity rather than a scientific technique, and the attentive monitoring required for transcribing can lead to the identification of unforeseen situations.

The chosen individuals received an interview consent form that was developed to manage the interview procedures. The interviews were conducted in Arabic, as the majority of participants preferred to speak their mother tongue. Memo writings and audio-visual recordings were utilized to help extract emerging information from interviewees (Charmaz, 2014). Immediately after the end of each session, I evaluated and classified the collected data (Hanna, 2012). Due to time limitations and COVID-19 restrictions, there was no pilot study. Instead, a member checking technique was applied, with the aid of two senior research colleagues, to confirm the study's trustworthiness (Nowell et al., 2017). The member checking technique was used to understand the participants' perspectives better and strengthen the interpretation of the obtained results. This procedure was repeated until I understood there would be no more coding and the interviews would not require any additional analysis (Sweidan, 2015).

In terms of research ethics, some of the entrepreneurs in this study stated that the only requirement for participating in the interview was confidentiality (Creswell, 2014). Therefore, to keep participants' identities anonymous, no other audio-video recording software was used. Additionally, settings for the Skype for Business 16 (KB4484213)'s meeting recordings, particularly those settings related to the permanent removal of the VoIP recordings from the principal researcher's computer, were managed to ensure participant confidentiality and privacy. This method ensures that all information is kept hidden from everyone except the principal researcher. 


\subsection{Data analysis}

The overarching goal of this research was to look at businesses' attitudes and concerns about P3 strategies in Egypt, as well as to develop a substantive theory based on the respondents' voices and experiences with the phenomenon. This was an immersive process that necessitated gathering and studying secondary and primary sources to gain a better understanding of the phenomenon. Theoretical perspectives started to emerge as the data was collected and analyzed, and after 12 tourism P3 and governance reports and 26 interviews, a saturation of the categories and their assets was achieved.

The Open Coding technique was used to code and analyze the data of Skype's conversations and texts (Charmaz, 2014). This qualitative analysis approach was designed to provide interim titles for data blocks that summarise what the researcher observed happening (not founded on current theory but based on the sense that arises from the data analysis) (Charmaz, 2014). Generally, open coding is the first stage of a qualitative data analysis technique and is usually followed by two subsequent stages, namely axial coding and selective coding (Charmaz, 2014). Eventually, these stages help to categorize the key concepts (codes), sub-issues, and issues that arose during the interview texts, with a focus on the labels and deeds utilized to determine businesses' perceptions toward the novel occurrences that may shake the P3s after the COVID-19 crisis in Marsa Alam.

This research largely used Charmaz's form of data analysis to verify that the data analysis procedure was robust. This form was combined with Corbin and Strauss's (1990, p. 13) coding approach to provide a platform for focused coding. This approach created awareness of the links between categories by bringing different data sets together into a coherent whole (Maher et al., 2018). Throughout the study, the investigator wrote notes and made comments to record evolving interpretations of the data. These were transcribed in a series of A4 hardcover diaries as well as in NVivo software. Both techniques for analysis were tested throughout the analytical method before choosing a combined approach (Maher et al., 2018).

Through the qualitative analysis process, computer-aided qualitative data analysis software (CAQDAS) (i.e., NVivo software) and traditional coding tools (e.g., paper, notepads, and highlighter pens) are used in combination. During the analysis process, this combination was proven to yield more theoretical insights. This allowed for more extensive involvement with the data from several perspectives, finally resulting in a solid GT generation analysis approach (Maher et al., 2018). This combined approach has the advantage of generating and recording the codes, as well as their relevant comments and notes in NVivo. Because it is quick and easy to collect, this approach allowed the investigator to stay close to the actual interview transcript, and it also helped maintain a clear digital trail, while the more interactive highlighter pens and notepads approach further supported the interpretation, observation, and constant comparison of data.

In this study, the NVivo 11.0 software program was used to analyze the participants' oral words that emerged in the open coding stage (Nowell et al., 2017). Qualitative researchers (especially grounded theorists) frequently employ computer software tools like NVivo to aid them in their data analysis (Hanna, 2012). The benefits of NVivo, as mentioned by Maher et al. (2018), are its data management capabilities and its capacity to provide answers to complicated quantitative inquiries about the data. On NVivo, all data may be saved digitally and retrieved promptly. It can be used in conjunction with other coding schemes.

Furthermore, Maher et al. (2018) claimed that NVivo facilitates sub-group analysis. For example, while using highlighter pens to highlight topics on paper, copies of transcripts may still be useful; looking at this information across a large number of participants is a difficult undertaking. As a result, NVivo software is useful for analyzing responses from various subgroups within the research sample (e.g., comparing what executives and employees said). In this vein, Kelle (1995) stated that qualitative research typically generates enormous quantities of complicated data sets, such as interview transcripts, which, if not properly handled, can result in data flood and researchers being fully immersed in the data. 
Through assembling, understanding, and investigating the observed primary data on worries that affect the redesigning of P3s after the COVID-19 crisis in Marsa Alam, 25 codes (core concepts) appeared to denote the concerns and beliefs of participants regarding the reshaping of the P3s. The collection of these 25 codes was not established beforehand but emerged based on data verification (Charmaz, 2014). To produce substantial GT, the emerging similarities between the expanded ideas (codes) yielded through the open coding stage should be combined into a common basis with one main category (Charmaz, 2014). This process-which represents the second stage of the qualitative data analysis method-allows jointly relating core codes (categories and features) through a mixture of deductive and inductive reasoning (Charmaz, 2014).

Concurrently, memo writing took place with the open coding process. According to Charmaz (2014), memos are used to chart the progress of theories, and if the method is followed correctly, the theory will be identified in the memos. Since coding necessitates constant comparisons of data (e.g., categories with other categories), memo writing aids in the recording of these procedures (Charmaz, 2015). Thus, the research process was led by the constant comparison of data, which is the backbone of GT. According to Matteucci and Gnoth (2017), constant comparison is a data-analytic method in which each understanding and result (e.g., declaration or occurrence) is compared to previous findings as it emerges from the data analysis until trends start to appear. Accordingly, the 25 codes (see Table 1) were rationalized into nine core categories of interconnected concepts according to the method of axial coding (Charmaz, 2014), including safety, involvement, marketing post-COVID-19, and agility.

Lastly, selective coding starts once substantive codes have reached saturation and a core category has emerged. In this vein, Charmaz (2014) stated that "theoretical sampling," which is not the same as conventional sampling, could be used to establish, clarify, or improve the features of provisional theoretical categories. This type of sampling makes the categories more resilient and accurate by increasing analytic complexity while remaining grounded in data (Charmaz, 2015). Therefore, theoretical sampling was used to concentrate and meet the analytic needs of the categories I created through the coding process. To sample theoretically with the aim of fulfilling the categories' analytic needs, I made a strategic decision about which data sets would be the most informative. In this context, Charmaz (2015) claims that theoretical sampling is similar to abductive reasoning in that unpredictable or confounding findings must be reasonably explained. The final output is theoretical category saturation, which happens when no new features of these categories or provisional categories can be discovered, and data may be paused as a result. Accordingly, relevant literature was reviewed and approached by taking advantage of the emerged codes and created issues.

Following the constructivist GT method's formal guidelines, four notable concerns were created regarding peripheral destinations' businesses' perceptions and attitudes on challenges confronting P3s after the COVID-19 crisis: employee rights, businesses' priorities, destination recovery challenges, and making the $\mathrm{P} 3$ s more joined-up.

Table 1

Emerged concerns from the coding process

\begin{tabular}{|c|c|c|}
\hline Codes (concepts) created from interview texts* & Sub-issues** & Concerns ${ }^{* * *}$ \\
\hline - Safe workplaces & \multirow{2}{*}{ - Safety } & \multirow{8}{*}{ - Employees'rights } \\
\hline - The horror of infection & & \\
\hline - Psychological and socio-economic concerns & \multirow{3}{*}{-Well-being } & \\
\hline - Employees retention & & \\
\hline - Employees mental health & & \\
\hline - Ending the reduction of household income & \multirow{3}{*}{ - Social security } & \\
\hline - Layoffs and shorter working hours & & \\
\hline - A government's furlough & & \\
\hline
\end{tabular}


Table 1 (continued)

\begin{tabular}{|c|c|c|}
\hline Codes (concepts) created from interview texts* & Sub-issues** & Concerns ${ }^{* * *}$ \\
\hline - Financial support & \multirow{3}{*}{ - Funding \& support } & \multirow{7}{*}{ - Businesses' priorities } \\
\hline - Sustainable stimulus packages & & \\
\hline - Government grants & & \\
\hline - The ambiguity of tourism policies & - Mitigating uncertainty & \\
\hline - Neglecting businesses' views & \multirow{3}{*}{ - Involvement } & \\
\hline - Involving the private sector & & \\
\hline - Entrepreneurs'ideas are beneficial & & \\
\hline - Moving business deals online & \multirow{5}{*}{$\begin{array}{l}\text { - Marketing } \\
\text { post-COVID-19 }\end{array}$} & \multirow{5}{*}{$\begin{array}{l}\text { - Destination's } \\
\text { recovery challenges }\end{array}$} \\
\hline - The need for digital marketing & & \\
\hline - Fascinating e-marketing tools & & \\
\hline - Re-building future tourism marketing strategies & & \\
\hline - The perks of peripheral destination experience & & \\
\hline - Public-private integration & \multirow{3}{*}{$\begin{array}{c}\text { - Commitment \& } \\
\text { responsiveness }\end{array}$} & \multirow{5}{*}{$\begin{array}{r}\text { - Making the P3s } \\
\text { more joined-up }\end{array}$} \\
\hline - Strategic commitment & & \\
\hline - Consistency is the key to overcoming the crisis & & \\
\hline - Adapting to transforming industry drives & \multirow{2}{*}{ - Agility } & \\
\hline - Promptness and agility are essential for fast-changing environments & & \\
\hline
\end{tabular}

*Emerged through the open coding stage. **Materialised through the axial coding stage. ***Rationalized through the selective coding stage.

\subsection{Research trustworthiness}

Trustworthiness is considered a proper criterion to demonstrate rigor in GT qualitative analysis (Charmaz, 2014). Trustworthiness is often ensured by utilizing conditions like credibility, transferability, dependability, and confirmability (Nowell et al., 2017). In order to address credibility, data collection triangulation was performed by employing multiple origins of data, such as data from Skype interviews, direct observations, and tourism business documents (Nowell et al., 2017) to help retain data related only to the P3s and the COVID-19 crisis in peripheral destinations.

So that those attempting to transfer the conclusions to their own context can estimate transferability, the researcher tried to provide fully detailed descriptions of the investigation, including the participants' profiles, utilized methods, explanation of results, and rising theory (Nowell et al., 2017). To establish dependability, an external auditor was invited to review the processes of data gathering and data interpretation and to examine the results of the research study (Charmaz, 2014). This happened to verify the conclusions' correctness and confirm that the findings are based on the gathered data (Charmaz, 2014). According to Nowell et al. (2017), achieving credibility, transferability, and dependability conditions establishes research confirmability. 


\section{Marsa Alam as a peripheral destination: Context and challenges}

Pociūté-Sereikienè (2019) reported that whilst some peripheral destinations are approaching state hubs, they are still recognized as peripheries due to the dominance of peripheral geographical and economic characteristics. This implies that, while location could be crucial for business success, other development factors determine business opportunities in the peripheral destinations context. As a model, Marsa Alam represents and proves this notion. Geographically speaking, Marsa Alam is the least established territory of the Red Sea governorate. With 8,553 inhabitants (as of the 2018 census), it is located on the outskirts of the governorate, almost 274 $\mathrm{km}$ from Hurghada, the well-developed and urbane regional center (Gohar \& Kondolf, 2020). Marsa Alam's location on the Red Sea's western coastline in south-eastern Egypt makes it closer to the historical rural areas of Upper Egypt than Cairo, Egypt's capital. Its reputation as a tourist destination was augmented following the opening of Marsa Alam’s International Airport in 2003 (Gohar \& Kondolf, 2020).

P3s are seemingly developed to empower local vulnerable businesses and peoples and to protect fragile resources at remotely located destinations, essentially by operationalizing their local socio-economic and environmental linkages with relevant government agencies (Sweidan, 2015). However, belated and inapt implementation, frequently led by individual concerns and priorities, has created absent-minded P3 solutions, particularly in hard times. This is especially apparent in the lack of inclusive dialogues between Marsa Alam's peoples and Egyptian government departments during the coronavirus crisis, contributing to underestimating the P3 conditions required to reduce COVID-19 crisis impacts on deprived people businesses and individuals.

As a result of the coronavirus crisis, the Egyptian government imposed a national curfew and lockdown in many tourist cities, including Marsa Alam (UNWTO, 2020). This situation triggered a dangerous business environment for those who invest in Marsa Alam's tourism projects. Moreover, the country's measures for reopening destinations made the coronavirus crisis even more difficult in such peripheral destinations. This is because the government has licensed hotels to return to business on the strict conditions that they work with a maximum of $25 \%$ capacity and fulfill a roster of sanitation standards to shield against the coronavirus (International Monetary Fund [IMF], 2020). All of these measures have been impulsively developed and implemented countrywide, leading to a reduction of the existing P3s' potential to mitigate COVID-19 impacts on vulnerable businesses and people.

Very few studies have investigated the role that agile P3s can play to achieve business success in the Egyptian peripheral destinations context. Marsa Alam is currently considered a booming destination but is still not in the same category as Hurghada, the Red Sea governorates' center (Gohar \& Kondolf, 2020). Arguably, any government attempts to reshape the $\mathrm{P} 3 s$ with entrepreneurs in peripheral areas should consider concerns such as accessibility and residential appeal.

In the wake of the COVID-19 crisis, government measures impelled several businesses to move their services online, with their employees working remotely (Ivanov et al., 2020). The ideas of 'working remotely' and 'reducing capacities' have been popular to help maintain businesses' durability and employees' wellbeing (OECD, 2020). However, the majority of peripheral destinations' businesses in Egypt, including Marsa Alam, face a serious issue with the adoption of automation technologies (Egyptian National Competitiveness Council [ENCC], 2013 (that are needed to tie businesses with government agencies from one side, and with domestic and international markets from another, to eventually help alleviate coronavirus concerns (Ivanov et al., 2020). Arguably, some destinations (i.e., peripherals) may be more economically or technologically challenging to adapt to reopening measures than others (i.e., cores)—particularly if there is a proven technological infrastructure that is prevailing in cores and lacking in peripherals.

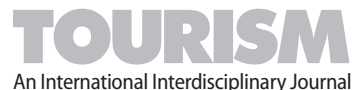


There is a consensus among tourism researchers that addressing the remoteness problem through digital connectivity between public, and private partners may help compensate ailing businesses economically (Ivanov et al., 2020; OECD, 2020). Enhancing digital connectivity should be a priority for peripheral destinations' P3 programs and policies, especially in times of adversity. In recent years, Egypt's Refreshed Tourism Strategy 2013-2020: The Way Forward and New Horizons has aimed to implement a new digital economy platform to improve business entrepreneurship and $\mathrm{P} 3 \mathrm{~s}$ in tourism destinations, including peripheral ones (ENCC, 2013). This initiative will attract more entrepreneurs to Marsa Alam's business opportunities and thrive with the new digital approach. However, enhancements in traditional transport and communication should not be neglected, as digital connectivity in such peripheral destinations needs more gradual and solid steps to be accommodated by local businesses and individuals.

During the coronavirus peak, Egypt's tourism industry lost about \$1 billion per month (Mabrouk, 2020). Marsa Alam's tourism businesses have been impacted remarkably hard by the decline, and the effects are deeply felt because it depends entirely on government support and interlinking with major tour operators of core destinations. Marsa Alam's tourism sector, which employs nearly 12\% of Marsa Alam's workforce, has witnessed unprecedented rates of mass layoffs and business closures (Mabrouk, 2020). This tampering occurred despite the government's decree to prevent employees' dismissal during the crisis, which reflects the fragility of current P3 solutions and their inability to contain the crisis impacts (Mabrouk, 2020).

Accordingly, the core argument here is that Marsa Alam is an example of the detrimental contextual position of implementing hard and inflexible P3 approaches in times of adversity. Current P3 solutions have failed to envisage and treat all the specific concerns and challenges of Marsa Alam's businesses and employees. Therefore, this study investigates relevant scientific grounds on managing $\mathrm{P} 3 \mathrm{~s}$ in peripheral destinations and to help extend them by considering their application in the wake of global health crises, where agile P3 practices are currently lacking.

\section{Findings}

\subsection{Respondents' profile}

All 26 participants of the tourism businesses of Marsa Alam were interviewed. Most interviewees were males $(n=18 ; 69 \%)$ and were over 51 years of age. The bulk of the participants were graduate degree holders $(n=21 ; 81 \%)$. Most of the participants $(n=22 ; 84.6 \%)$ engaged in the drafting of prior $\mathrm{P} 3 \mathrm{~s}$ with various government departments. The majority $(n=19 ; 73 \%)$ have worked in the tourism sector of Marsa Alam for five years or more. Finally, most participants $(n=18$; 69\%) represented 4 - and 5 -star hotels and tourism resorts. As a result, they were well aware of the needs and goals of the Marsa Alam tourism industry, as well as the pressing needs of both businesses and employees during the recurring crises facing the tourism industry in Marsa Alam. Overall, the predominant vulnerability problems faced by these interviewees in the COVID-19 crisis were more than expected, so they could not survive under the lockdown measures imposed by the Egyptian government.

\subsection{Businesses' perspectives on $\mathrm{P} 3$ issues}

The main aim of conducting this investigation was to gain a deeper understanding of COVID-19's effect on the future of $\mathrm{P} 3 \mathrm{~s}$ and to help generate new ideas about this phenomenon in times of global crisis. The findings of this investigation show that employees' rights, businesses' priorities, destinations' recovery challenges, and making P3 more joined-up are significant issues in the recovery, restart, and agile P3 responses of peripheral destinations. The sub-sections that follow go through these issues in greater depth. 


\subsubsection{Employees' rights}

Three subtopics concerning employees' rights are designated: 'safety', 'well-being' and 'social security'. Regarding 'safety', the surveyed entrepreneurs and executives believed that their businesses would be more impaired during the coronavirus pandemic if their employees were exposed to health hazards. More precisely, they sensed that the condition of the businesses is vulnerable since these employees are not protected from the pandemic risks. This implies that they must do whatever they can to promote their health protection. Another promising finding was that almost $60 \%$ of respondents emphasized that businesses' employees have the right to a safe workplace climate in Marsa Alam during the pandemic crisis. However, the majority of participants $(n=23 ; 88.4 \%)$ insisted that they cannot afford to simultaneously pay for both employees' salaries and the expenses of satisfying new safety requirements. For example, a 4-star hotel entrepreneur pointed out that:

Financial assistance and safety protection for our staff is a professional and ethical obligation in times of crisis, but an expensive safety solution is meant for temporary intervention in very particular circumstances. We are facing a time of confusion in which we have no deadline and no sense of how the system will be like after the ongoing situation. Nothing so far, particularly the existing P3 efforts, improves our ability to provide constant financial assistance, protection measures and constructive acts when attempting to address the current crisis.

The second subtopic, 'well-being', refers to businesses' ability to promote employees' well-being and stamina amid the worsening COVID-19 pandemic. For the majority of the interviewees, the crisis has potentially fatal implications for the physical health of their staff. Yet, the effects of mental well-being-exhaustion, fear, and uncertainty_may also be called harmful. As business leaders, they believe they are responsible for improving the well-being of their workers. Specifically, three-quarters of the interviewees were concerned about the vulnerability of their frontline service workers (e.g., receptionists, drivers, and bell boys) to lethal coronavirus threats. In fact, at least $82 \%$ of participants wished to consider the agile response to existing P3 strategies expressly tailored to resolve the mental, psychological and physical wellbeing issues affecting frontline workers rather than the second-line workforce (e.g., accountants and marketing staff), who are less vulnerable to pandemic threats, as indicated by a travel agency executive:

Frontline employees, such as tourist bus drivers and tour guide leaders, are working harder and closer to an unknown and potentially deadly threat. Businesses must now deal with staff stress and the tension that comes with desire to succeed during a crisis, in addition to keeping people safe. Some people may be afraid of guilt if their work keeps them from supporting their own families; others may suffer because they purposely avoid contact with their family members for fear of spreading disease. Although those working remotely, or so-called second-line employees, face the emotional burden of isolation as well as the physical challenges of unfamiliar workspaces (e.g., dining rooms and living rooms) that are difficult to find that suits the mission, they still have a substantially lower risk of coronavirus exposure than frontline employees.

The third subtopic is 'social security'. The surveyed businesses of the Marsa Alam tourism industry have insisted that the reshaping of the P3 programs must lead to the perfection of the social security of their employees. A 5-star hotel general manager stated::

Formulating social security policies at the core of the $\mathrm{P} 3$ interventions will make a major contribution to their success in minimizing employee layoffs and reduced working hours, thus improving the resilience of individuals in the face of shocks. This entails identifying social security not as an emergency solution to a crisis situation or as a charity, but rather as a collection of perpetual government benefits set out in the P3s, establishing tourism workforces as rights holders, and ensuring them access to autonomous claims processes if they are refused the compensation they apply for during times of crisis. Recruitment of business solidarity and government resources should be at the disposal of this goal while rethinking the advancement of current $\mathrm{P} 3$ strategies.



An International Interdisciplinary Journal 


\subsubsection{Businesses' priorities}

Three business priority axes were generated: 'funding \& support', 'mitigating uncertainty', and 'involvement'. Concerning the first axis, participants ranked government financial support as a top priority, particularly to help pay wages and to meet health measures. Interviewee 14 pointed out that:

The complexity of the coronavirus crisis and the locking and quarantine policy initiatives adopted in response now have a major impact on the earnings and liquidity of tourism and hospitality companies in many of the affected destinations, and in particular, on businesses based in peripheral areas, such as Marsa Alam, which have traditionally had fewer own capital and little access to external financing except for their banks. Thus, if the government would prevent the tourism industry from collapsing, with a large proportion of its vulnerable companies being forced to shut down activities, it would be necessary to get financial support from outside (i.e. a government financial intervention) and promptly through a new P3 funding solution.

For the second axis, 'there is a great deal of uncertainty,' the entrepreneurs and executives critiqued government P3 policies aimed at reducing the exacerbation of market uncertainty and dealing with challenging situations. More than $60 \%$ of interviewees disagreed with the effectiveness of current P3 methods and techniques intended to mitigate the extent of market instability in times of crisis to help them return to normal life in six months or less. In their interviews, participants 5, 13, 15, 18, and 22 explained the reasons behind the disagreement. Participant 22 clarified that:

In the tourism business context, the only real certainty lies in business uncertainty. Natural catastrophes, terrorist attacks, economic downturns, pandemics such as COVID-19, and a variety of other possible disruptions occur regularly. And while it is increasingly important to have strategies to endure these crises, innovative private and public partners together are now able to use moments of crisis as opportunities to boost their market position and strategic resilience through the benefit of the uncertainty or so-called 'uncertainty advantage' threshold. This can be achieved by moving well beyond the conventional sense of tourism crisis management-i.e., finding innovative $\mathrm{P} 3$ opportunities to accomplish the best of the worst outcomes- to build fresh and sustainable value out of uncertainty by seeing the unexpected as a competitive edge and an opportunity to launch creative strategies that cater to the 'new normals' of tourists, companies, stakeholders, policymakers and the peripheral destination community. Unfortunately, this pattern is not supported by current $\mathrm{P} 3$ responses. Instead, they hinder the capacity of the private sector to operate on its own in light of the regulations enforced by the government without involving the private sector, which raises uncertainty.

Private sector 'involvement' is the third business priority axis. Typically, P3 is about engaging public and private players in coping with the industry's challenges rather than doing so on their own or transferring them to the business (Sweidan, 2015). However, the intricacy of such P3s poses significant questions about cooperation transparency and the role of businesses in times of adversity. Half of the respondents seemed to see themselves as a positive factor in the existing P3s' development to help prevent the recovery context from worsening. A 5-star hotel businessperson said:

Some of the respondents had worked with government authorities in formulating tourism development plans before, and thus Marsa Alam's tourism private sector community is an integral part of the crisis solution that can provide hope for Marsa Alam's tourism industry. The government should take the views of the private tourism sector seriously. These former 'private' tourism development plans' experts build a bridge between the government and the tourism community of Marsa Alam. The interviewee also pointed out the need for equality in the participation of the private sector of all tourist destinations at the country level, provided that, in particular, Marsa Alam needs to be presented by industry people who can identify the main problems of the sector. For example, the involvement of the hospitality sector of Marsa Alam will help to highlight the 
need to postpone diesel consumption charges during the worsening coronavirus crisis, given that this peripheral destination does not rely on electricity for hotel and resort operations.

Moreover, one-third of the participants shared a desire to get actively involved in the reshaping activities of the P3s with guidance, monitoring, and counseling.

\subsubsection{Destinations' recovery challenges}

Concerning 'post-crisis marketing strategies' as a part of businesses' concerns and challenges, which are related to the concept of a destination's recovery (Ivanov et al., 2020), the great majority of the respondents tended to regard $\mathrm{P} 3$ as a key asset in enhancing business resilience and creating innovative digital marketing opportunities in the wake of the coronavirus crisis. For example, participant 9 said:

As far as the tourism industry is concerned, investment in the digital technology of tourism and hospitality marketing initiatives is also pursued with creative P3 solutions. For example, those P3 infrastructure initiatives that encourage the private sector's use of e-marketplaces, artificial intelligence, big data, search engine algorithms, as well as digital marketing videos, photos, paid social media and affiliate e-marketing campaigns will boost virtual mental availability and 24/7 surveillance, minimizing physical unavailability threats in the aftermath of the coronavirus crisis.

Also, the majority of respondents $(n=20 ; 77 \%)$ agreed that, rather than waiting for recovery to begin, companies are more likely to succeed if they act quickly to gain digital market share through downturns. This versatility, combined with an emphasis on tourism value and security support, also gives businesses a pioneering edge that other competitors (who lack digital marketing solutions) cannot afford. In the next normal, the first movers, with the aid of $\mathrm{P} 3 \mathrm{~s}^{\prime}$ programs, to e-marketing during the current crisis could recover stronger.

\subsubsection{Making the P3s more joined-up}

Two aspects of being a 'joined-up' P3 were identified as a result of the semi-structured interviews: 'commitment and responsiveness' and 'agility'. Firstly, OECD (2020) indicates that government responsiveness to market issues and commitment to business risk avoidance obligations in the wake of COVID-19 are related to the idea of 'joined-up P3', which suggests that government agencies should aim to reposition their partnership practices with the private sector and to 'deliver' revolutionary interventions to businesses and their employees so that they can be as productive as possible during difficult times. Participants 3, 9, 12, 15, and 26 stated that public-private collaboration is performed regularly in times of crisis but is not often consolidated and coordinated. Participant 15 stated:

A more streamlined P3 structure would offer benefits to the tourism sector of Marsa Alam-a better joined-up P3 means a real change for vulnerable companies and individuals to COVID-19, with those with comparatively small financial capital most at risk. Understanding which businesses and individuals are most endangered in the tourism environment of Marsa Alam will help other businesses respond to the crisis with well-coordinated P3 solutions.

Secondly, 'joined-up P3' also includes 'agile cooperation' between government entities to deliver outcomes and address cross-cutting industry challenges that could not be achieved by a single agency working alone (Williams et al., 2020). The majority of respondents $(n=21 ; 81 \%)$ stressed that the promptness and agility of $\mathrm{P} 3$ solutions were important for businesses operating in fast-changing environments. The topic of agility was posed by participant 5 :

While conventional P3 solutions concentrated on reducing costs and enhancing back-office facilities in periods of crisis, today's P3 solutions can concentrate more on facilitating teamwork through agile industry teams to consolidate services, a business that cannot rapidly develop itself, evolve, reinvent and accelerate development while battling its recovery threats in the face of the unparalleled coronavirus crisis. 


\section{Discussion of findings}

The proposed substantive theoretical proposition of this study aims to link and incorporate the major aspects that characterize the phenomenon (i.e., businesses' concerns about P3 responses) under investigation (Matteucci \& Gnoth, 2017). Through understanding and integrating the categories revealed in Table 1, the substantive theoretical proposition allows for a holistic view of the phenomenon. From this angle, it is possible to observe, for example, that it is important to consider employees' rights in times of pandemic crisis in order to alleviate businesses' concerns about $\mathrm{P} 3$ responses. Also, the investigation shows that having a strategic commitment from P3 actors is necessary to obtain more joined-up P3s. Similarly, a well-connected P3 is essential for the existence of effective business recovery solutions, which, in turn, would interfere directly with the actors' recovery solution consistency.

In particular, the study discovered fresh theoretical insights for 'businesses' concerns' regarding P3 responses in uncertain times, as detailed in Table 1, which differs from the typical perspective offered in the theoretical literature and summarised by earlier studies. For example, Chaperon (2017) and Wondirad et al. (2020) defined three core features (i.e., involvement as a business priority, cross-sector alliances, and stakeholder collaboration) that are common as the primary concerns of businesses in terms of tourism P3 responses. These characteristics are used in academic literature to compare and contrast P3 strategies and core categories.

However, the current study revealed that in times of uncertainty, businesses' concerns in the examined context have only one similar theme with the conventional understanding of businesses' concerns about P3 response conceptualization: the private sector's involvement in tourism governance as a business priority. Unlike this view, the investigation's substantive findings show that employees' rights, business priorities, destination recovery challenges, and making P3 more joined-up are substantive categories that interpret businesses' concerns about $\mathrm{P} 3$ responses.

Moreover, the phenomenon of 'business vulnerability' during pandemic crises is a substantive field, and a substantive theoretical insight of this phenomenon is developed through research amongst individuals (i.e., tourism entrepreneurs and executives) within the same substantive area (P3). In particular, a study of ailing businesses in which entrepreneurs, executives, and employees are all battling pandemics at diverse paces could reveal important theoretical considerations about effective $\mathrm{P} 3$ responses that may mitigate the business vulnerability. These relationships emerged from the data, as observed in Table 1.

The study findings reveal that governments and business entrepreneurs have had to make swift decisions during COVID-19, a time for which there is no blueprint, particularly for the context of peripheral destinations. Entrepreneurs now need to navigate a 'new normal' with consequences for employees' rights (Carr, 2020). These findings go beyond prior research (i.e., Chaperon, 2017; UNWTO, 2020), demonstrating that while maintaining a safe environment is a must for workers, it is difficult in this ongoing recession to bear the cost of wages, the costs of providing additional safety standards and other operating costs. This may be the reason why Marsa Alam businesses have not considered existing P3 policies to be effective in handling these emerging concerns.

Furthermore, the results demonstrate that capitalizing on the private sector's priorities in peripheral destinations will help drive positive progress in $\mathrm{P} 3$ policies and encourage collaborative principles to make a step ahead in the way decisions are taken in the aftermath of COVID-19. Travel agency participants focus their priorities primarily on protecting frontline staff, such as drivers and tour leaders, as they are exposed to a direct risk that can harmfully affect work stoppages. These variances are in line with the OECD (2020)'s study, which stated that the highest priority of many hotel companies is to rescue financial fragility and plan debt payments to comply with volatile revenue fluctuations, while the primary concern of travel agencies and airlines is to reduce their workers' vulnerability to pandemic threats. 
Regarding the recovery problems and issues of the peripheral destination businesses that may influence the reshaping of $\mathrm{P} 3$ strategies, the findings indicate that Marsa Alam tourism and hospitality companies are more concerned about government responses that exploit technical resources and digital marketing opportunities to quickly allow the private sector to remain linked to 'new normal' marketplace contexts in the wake of COVID-19. This finding is in line with the Ivanov et al. (2020) study, which indicates that allowing automated tourism business solutions provided by government programs will facilitate the achievement of competitive marketing goals during and after the crisis.

Turning to the challenge of making P3s more joined-up, it can be argued that, for outsiders, tourism companies benefit from Egypt's P3 scheme, a national development initiative in which private companies, funded by public investment, have access to a mix of development solutions, grants, technical assistance and incentive packages that they need to keep them running (ENCC, 2013). However, the degree of fragmentation that occurs in the Egyptian P3 structure, especially in times of crisis, has hit businesses in peripheral destinations and even businesses from national core tourism destinations. In this sense, the investigation reveals that the majority of participants found engagement with the Egyptian government agencies challenging, scattered, and less united than the competing countries. This establishes obstacles for businesses to successfully adapt and makes Egyptian destinations less appealing for business activity. Recent findings from Ivanov et al. (2020) and UNWTO (2020) indicate that integration and agility are crucial aspects for tourism businesses operating in fast-moving contexts. This is also evident from the present study results.

\section{Conclusion and implications}

In response to the OECD (2020)'s argument that irresponsive P3 models are prevalent in developing countries due to the lack of public-private policy dialogues, the current study adds substantive theoretical insight to the established knowledge of $\mathrm{P} 3$ management and peripheral destination growth in times of crisis. This study offers empirical evidence for valid business concerns and distinct P3 patterns from a well-known Egyptian peripheral destination. The study results indicate that businesses considered collaboration with government agencies difficult, fragmented, and less unified, and the responsive collaboration has suffered. Therefore, the collaborative advantages of the joined-up P3 model were addressed and understood in the context of Marsa Alam's business concerns and perceptions.

The investigation has both theoretical and managerial implications. As for its contribution to tourism theory, the newly-added concerns and perceptions provide significant empirical evidence that peripheral destinations' businesses, with experienced $\mathrm{P} 3$ engagements, can provide applicable P3s ideas to help mitigate pandemics' perils, enhance business recovery, and recognize employees' rights through the 'uncertainty advantage' threshold. Turning uncertainty into a value idea is in line with some of the previous research (e.g., Carr, 2020; Ivanov et al., 2020), which enhances the validity of the empirical evidence obtained from this investigation.

Regarding managerial implications, the study provides evidence that the role of tourism entrepreneurs and executives in strengthening P3 strategies and influencing government responses in times of adversity in peripheral destinations is undeniable. Seeking responsive and agile $\mathrm{P} 3$ solutions in many peripheral destinations is very challenging, if not impossible, without understanding the concerns and perceptions of businesses. However, the participation of tourism entrepreneurs and executives in the post-pandemic P3 reshaping phase is not a simple decision to be employed by government agencies in developed countries due to a lack of creative resources for shared dialog and trust between P3 parties (Sweidan, 2015).

As a result, it is suggested that the government proceed with caution while pursuing "joined-up" collaborative initiatives in order to allow businesses and executives to benefit from P3 responses. This may eventually contribute to establishing a new P3 framework to aid in coping with post-pandemic threats (Dewulf \& Garvin, 
2019). In destination and tourism crisis management theories, that peril is specified not only by the pandemic issues (the perils) but also by the industry elements' exposure and vulnerability to these perils (Carr, 2020). Therefore, pandemic-responsive P3s, active crisis adaptation, and sufficient recovery management strategies and pursuits should depend on a precise perception of the extent of the threat and vulnerability, along with an adequate evaluation of variations to this extent (Chaperon, 2017).

In terms of study limitations, this research has three major constraints that should be addressed in future research. First, the research is limited in its use of entrepreneurs and executives of peripheral destination businesses as participants. Second, the effects of the crisis risk allocation and the commitment of the public/ private sectors were not included in the research. Third, because all interviews took place over such a short period of time during the Covid-19 outbreak, the "theoretical sampling" method was not fully implemented in this study, potentially limiting the GT approach. Future studies might assess the benefits and drawbacks of P3 strategies from the viewpoints of residents of peripheral destinations, as well as entrepreneurs, executives, and employees who work in these destinations. Quantitative analysis should also be undertaken to examine the commitment gaps of $\mathrm{P} 3$ partners and their effect on the policies of $\mathrm{P} 3$ in peripheral destinations. Future constructivist GT research should suitably use the theoretical sampling approach to acquire more data based on the concepts developed during the original data analysis. As a result, future constructivist GT research attempting to build a new theory in the research field may be more rigorous.

\section{Acknowledgments:}

I would like to thank the helpful reviewers for their informative remarks on the first round of submissions, which helped me improve the overall quality of my work, especially the Methodology chapter.

\section{References}

Carr, A. (2020). COVID-19, indigenous peoples and tourism: A view from New Zealand. Tourism Geographies, 22(3), $491-502$. https://doi.org/10.1080/14616688.2020.1768433

Chaperon, S. (2017). Tourism industry responses to public-private partnership arrangements for destination management organisations in small island economies: A case study of Jersey, Channel Islands. International Journal of Tourism Policy, 7(1), 23-41. https://doi.org/10.1504/IJTP.2017.10003750

Charmaz, K. (2014). Constructing grounded theory: A practical guide through qualitative analysis. Sage.

Charmaz, K. (2015). Grounded theory: Methodology and theory construction. In International encyclopedia of the social \& behavioral sciences (2nd ed., 10, pp. 402-407). http://dx.doi.org/10.1016/B978-0-08-097086-8.44029-8

Čorak, S., Živoder, S.B., \& Marušić, Z. (2020). Opportunities for tourism recovery and development during and after COVID-19: Views of tourism scholars versus tourism practitioners. Tourism: An International Interdisciplinary Journal, 68(4), 434-449. https://doi.org/10.37741/t.68.4.5

Corbin, J., \& Strauss, A. (1990). Grounded theory research: Procedures, canons and evaluative criteria. Qualitative Sociology, 13, 3-21.

Creswell, J. (2014). Research design: Qualitative, quantitative, and mixed methods approaches (4th ed.). Sage. http://www.drbrambedkarcollege.ac.in/sites/default/files/Research-Design_Qualitative-Quantitative-and-MixedMethods-Approaches.pdf

Dewulf, G., \& Garvin, M. (2019). Responsive governance in PPP projects to manage uncertainty. Construction Management and Economics, 1-15. https://doi.org/10.1080/01446193.2019.1618478

Egyptian National Competitiveness Council. (2013). Refreshed tourism strategy 2013-2020:

The way forward and new horizons.

file:///C:/Users/mekaw/Downloads/RefreshedTourismStrategy2013-2020TheWayForwardandNewHorizons.pdf 
Etikan, I., Musa, S.A., \& Alkassim, R.S. (2016). Comparison of convenience sampling and purposive sampling. American Journal of Theoretical and Applied Statistics, 5(1), 1-4. https://doi.org/10.11648/j.ajtas.20160501.11

Gibson, B., \& Hartman, J. (2014). Rediscovering grounded theory. Sage.

Gohar, A., \& Kondolf, G. (2020). How eco is eco-tourism? A systematic assessment of resorts on the Red Sea, Egypt. Sustainability, 12(23), 1-20. https://doi.org/10.3390/su122310139

Hall, C.M. (2011). A typology of governance and its implications for tourism policy analysis. Journal of Sustainable Tourism, 19(4-5), 437-457. https://doi.org/10.1080/09669582.2011.570346

Hanna, P. (2012). Using internet technologies (such as Skype) as a research medium: A research note. Qualitative Research, 12(2), 239-242. https://doi.org/10.1177/1468794111426607

Huxham, C., \& Vangen, S. (2000). Leadership in the shaping and implementation of collaboration agendas: How things happen in a (not quite) joined-up world. Academy of Management Journal, 43(6), 1159-1175. https://doi.org/10.2307/1556343

International Monetary Fund. (2020). Policy responses to COVID19. IMF Publishing. https://www.imf.org/en/Topics/imf-and-covid19/Policy-Responses-to-COVID-19

Ivanov, S.H., Webster, C., Stoilova, E., \& Slobodskoy, D. (2020). Biosecurity, crisis management, automation technologies and economic performance of travel, tourism and hospitality companies - A conceptual framework. Tourism Economics, 1-24. https://doi.org/10.1177/1354816620946541

Kelle, U. (Ed.) (1995). Computer-aided qualitative data analysis. Sage.

Lai, K., \& Li, Y. (2012). Core-periphery structure of destination image. Annals of Tourism Research, 39(3), $1359-1379$. https://doi.org/10.1016/j.annals.2012.02.008

Mabrouk, M. (2020). Introduction: Evolution, adaptation, and survival. In M. Mabrouk (Ed.), Rethinking Egypt's economy (1st ed., pp. 1-4). Middle East Institute. https://www.mei.edu/sites/default/files/2020-10/Rethinking\%20Egypt\%27s\%20Economy.pdf

Maher, C., Hadfield, M., Hutchings, M., \& de Eyto, A. (2018). Ensuring rigor in qualitative data analysis. International Journal of Qualitative Methods, 17(1), 1-13. https://doi.org/10.1177/1609406918786362

Martin, R., Sunley, P., Gardiner, B. \& Tyler, P. (2016). How regions react to recessions: Resilience and the role of economic structure. Regional Studies, 50(4), 561-585. https://doi.org/10.1080/00343404.2015.1136410

Matteucci, X., \& Gnoth, J. (2017). Elaborating on grounded theory in tourism research. Annals of Tourism Research, 65(1), 49-59. https://doi.org/10.1016/j.annals.2017.05.003

Mekawy, M. (2019). Building a destination-operating model for successful transformation during adversity: The case of Sharm el-Sheikh, Egypt. Tourism: An International Interdisciplinary Journal, 67(2), 185-201.

Nowell, L.S., Norris, J.M., White, D.E., \& Moules, N.J. (2017). Thematic analysis: Striving to meet the trustworthiness criteria. International Journal of Qualitative Methods, 16(1), 1-13. https://doi.org/10.1177/1609406917733847

Organization for Economic Co-operation and Development. (2020). Tourism policy responses to the Coronavirus (COVID-19). OECD Publishing. http://www.oecd.org/Coronavirus/policy-responses/tourism-policy-responses-to-theCoronavirus-covid-19-6466aa20/

Pernecky, T., \& Jamal, T. (2010). Hermeneutic phenomenology in tourism studies. Annals of Tourism Research, 37(4), 1055-1075. https://doi.org/10.1016/j.annals.2010.04.002

Pociūtè-Sereikienė, G. (2019). Peripheral regions in Lithuania: The results of uneven development. Regional Studies, Regional Science, 6(1), 70-77. https://doi.org/10.1080/21681376.2019.1571437

Prideaux, B. (2002). Building visitor attractions in peripheral areas - Can uniqueness overcome isolation to produce viability? International Journal of Tourism Research, 4(5), 379-389. https://doi.org/10.1002/jtr.387

Schmallegger, D., Carson, D., \& Tremblay, P. (2010). The economic geography of remote tourism: The problem of connection seeking. Tourism Analysis, 15(1), 125-137. https://doi.org/10.3727/108354210x12724734537551

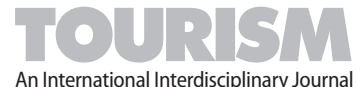

Moustafa A. Mekawy

Businesses' Concerns About Public-Private Partnership Responses Toward COVID-19, Egypt 
Sweidan, N.D. (2015). Strategies to sustain public-private partnership: A Lebanese agency case study [Doctoral dissertation]. Walden University. https://scholarworks.waldenu.edu/dissertations/?utm_campaign=PDFCoverPages\&utm_ medium=PDF\&utm_source=scholarworks.waldenu.edu\%2Fdissertations\%2F1869

United Nations World Tourism Organization. (2020). UNWTO briefing note - Tourism and COVID-19, Issue 2 - How are countries supporting tourism recovery? UNWTO Publishing.

https://webunwto.s3.eu-west-1.amazonaws.com/s3fs-public/2020-06/BFN_V4.pdf

Williams, A.M., Rodriguez, I., \& Makkonen, T. (2020). Innovation and smart destinations: Critical insights. Annals of Tourism Research, 83, Article 102930. https://doi.org/10.1016/j.annals.2020.102930

Wondirad, A., Tolkach, D., \& King, B. (2020). Stakeholder collaboration as a major factor for sustainable ecotourism development in developing countries. Tourism Management, 78, Article 104024. https://doi.org/10.1016/j.tourman.2019.104024

Zenker, S., \& Kock, F. (2020). The Coronavirus pandemic - A critical discussion of a tourism research agenda. Tourism Management, 81, Article 104164. https://doi.org/10.1016/j.tourman.2020.104164

Received: February 20, 2021

Revised: April 19, 2021

Revised: May 31, 2021

Revised: July 05, 2021

Accepted: July 19, 2021 